\title{
Relation between family physician retention and avoidable hospital admission in Newfoundland and Labrador: a population-based cross-sectional study
}

\author{
John C. Knight PhD, Maria Mathews PhD, Kris Aubrey-Bassler MD MSc
}

\section{Abstract}

Background: Physician turnover, involving physicians' leaving clinical practice in a specific area, may disrupt continuity of care, leading to poorer health outcomes and greater use of health care services. The purpose of this study was to investigate the relation between family physician retention and avoidable hospital admission for ambulatory-care-sensitive conditions.

Methods: We conducted a population-based cross-sectional study using provincial health administrative data for residents of Newfoundland and Labrador who held a provincial health card between 2001 and 2009. Five-year family physician retention was calculated by regional economic zone, and residents within economic zones were grouped into tertiles based on physician retention level. We compared hospital admission for ambulatory-care-sensitive conditions among tertiles while adjusting for covariates.

Results: For 475691 residents of the province, there was a negative relation between physician retention and hospital admission for ambulatory-care-sensitive conditions: residents of areas with moderate or low physician retention had admission rates that were $16.5 \%$ (95\% confidence interval $[\mathrm{Cl}) 12.6 \%-20.4 \%)$ and $19.9 \%(95 \% \mathrm{Cl} 15.2 \%-24.7 \%)$ higher, respectively, compared to areas with high retention. No relation was found when analysis was limited to those aged 65 years or more.

Interpretation: The findings suggest that high physician retention is associated with lower rates of hospital admission for ambulatorycare-sensitive conditions even after control for other factors. This is consistent with our hypothesis that physician turnover acts to disrupt continuity of care, resulting in higher admission rates.

\section{$\mathrm{R}$} elational continuity of care with a primary care physician has been associated with improved problem recognition, ${ }^{1}$ preventive care,,-4 patient satisfaction and treatment adherence ${ }^{5-9}$ as well as reduced use of health care services,${ }^{10-17}$ health care costs ${ }^{18-20}$ and mortality. ${ }^{21-23}$ However, relatively little is known about the effects of a specific aspect of continuity of care, primary care physician turnover. ${ }^{24}$ Physician turnover, which involves a physician's leaving clinical practice in a specific area, may disrupt continuity of care by diminishing opportunities for establishing trusting physicianpatient relationships and reducing the quality of communication and information needed for care. ${ }^{25-27}$ Patients forced to change their family physician report low satisfaction with care and loss of trust, ${ }^{28}$ whereas higher physician retention has been shown to be associated with better patient satisfaction and preventive care outcomes ${ }^{25-27,29}$ and may be associated with reduced use of health care services.

Although several studies have shown that higher continuity with a primary care physician is associated with reduced pre- ventable hospital admissions for ambulatory-care-sensitive conditions, ${ }^{13,14,17,30}$ we were unable to find any studies examining the relation between physician turnover/retention and hospital admission. Studying the effects of retention is important because changes to health policy required to address this issue are different from those for continuity. In addition, measuring physician turnover or retention may offer a proxy measure for continuity of care when it is not possible to measure continuity at the individual level.

Newfoundland and Labrador has a long history of physician shortages, exacerbated by the out-migration of physicians.

\section{Competing interests: None declared.}

This article has been peer reviewed.

Correspondence to: John Knight, john.knight@med.mun.ca

CMAJ Open 2017. DOI:10.9778/cmajo.20170007 
Between 2011 and 2015, the province had the second-highest average annual net loss of physicians of all Canadian provinces and territories. ${ }^{31}$ The goal of the present study was to investigate the association between physician retention and hospital admissions for ambulatory-care-sensitive conditions through linkage and analysis of health administrative data in Newfoundland and Labrador.

\section{Methods}

\section{Setting, design and participants}

This was a population-based cross-sectional study set in Newfoundland and Labrador, which had a population of 505469 in the 2006 Canadian census. The study sample was distributed across 269 (91.5\%) rural and 25 (8.5\%) urban centres (census subdivisions). We studied a cohort of patients investigated in a prior analysis of effects of primary care reforms (unpublished data, 2017) consisting of residents of the province who held a provincial health card between 2001 and 2009. Residents who changed postal code or permanently left the province between 2001 and 2009 were excluded.

\section{Data sources and procedure}

We obtained patient records including age, sex and postal code from the provincial health insurance registry. We linked records to provincial hospital abstracts, physician claims and death records for the 5-year period 2005-2009. We obtained information on family physician supply and retention from the Physician and Medical Practice Database, a longitudinal research data set of physicians in Newfoundland and Labrador. Provincial databases containing hospital abstracts and death records are used for research and policy and planning and undergo rigorous quality procedures. ${ }^{32,33}$ Data elements from abstracts are extracted and validated annually and have been found to be highly accurate and complete (Rosalie Haire, Newfoundland and Labrador Centre for Health Information, St. John's: unpublished data, 2004). ${ }^{33}$ Physicians' claims data are generally considered to be complete given that the information collection is required for physicians to obtain payment for services. $^{34}$

We mapped postal code of residence to census dissemination areas (i.e., neighbourhoods) using the Postal Code Conversion File. ${ }^{35}$ We obtained several covariate variables, including median household income and proportions of residents reporting high school completion, Aboriginal identity and visible minority status, from the 2006 Canadian census at the level of dissemination area. ${ }^{36}$ In addition, we used the Postal Code Conversion File to map postal code of residence for each resident to 1 of 20 provincial economic zones ${ }^{37}$ (Appendix 1, available at www.cmajopen.ca/content/5/4/E746/suppl/DC1).

\section{Measures}

\section{Main predictor variable and outcome}

Physician retention was the main predictor of interest and was defined as proportion of physicians practising in a given economic zone at the start of 2005 who were still practising in that zone at the end of 2009 (5-yr retention). ${ }^{38}$ We chose economic zone rather than community to calculate retention because we felt that this level of geography most accurately reflected accessibility of family physician care. Many communities in Newfoundland and Labrador have a small number of physicians practicing in them and are in close proximity to other communities. When we calculated retention at the community level, the departure of 1 physician from a small area resulted in large changes in retention score that often did not reflect the actual change in accessibility because of the availability of physicians in nearby communities. The larger geography of the economic zones allowed us to more accurately capture this accessibility ${ }^{37}$ (Appendix 1).

We then assigned 5-year physician retention values for each economic zone to residents based on postal code of residence, and residents were grouped into tertiles $(0 \%-33 \%$, $34 \%-66 \%, 67 \%-100 \%$ ) based on their retention score. With patient as the unit of analysis, we examined the number of hospital admissions for ambulatory-care-sensitive conditions (including chronic, acute and vaccine-preventable conditions $^{39}$ ) for residents in each retention tertile. Conditions examined and codes used to define them were slight variations of those used in a previous Canadian study ${ }^{39}$ and are included in Appendix 2 (available at www.cmajopen.ca/content/5/4/ E746/suppl/DC1).

\section{Covariates}

Covariates found to be associated with use of health care services were included as control variables in the analysis. We calculated Charlson Comorbidity Index values for each patient using diagnostic codes contained in physician billing data $^{40}$ and grouped the values into 4 categories (0, 1-2, 3-4 or $\geq 5$ ). The values were grouped into 4 categories because there were relatively few patients with a higher number of comorbidities. Including more than 4 categories was associated with only minimal improvement in the predictive ability of the models (minimal reduction in the Akaike information criterion).

We calculated income quintiles for each dissemination area as described in a previous study, in which they were found to be good predictors of use of health care services. ${ }^{41} \mathrm{We}$ also calculated proportions of residents in dissemination areas reporting high school completion, Aboriginal identity and visible minority status. We determined residence status (rural or urban) by census subdivision (i.e., municipality) from 2006 census data. We assigned dissemination-area-level covariates to patients using the residential postal code. Census subdivisions were considered urban if they fell within a census metropolitan area or census agglomeration; otherwise they were considered rural. ${ }^{36}$

We determined the mean number of acute care hospital beds per 1000 residents (hereafter beds per capita) by assigning each census subdivision to the nearest acute health care facility using ArcGIS version 10.3 geospatial software (Environmental Systems Research Institute). We obtained the number of acute care beds in each facility from the Guide to Canadian healthcare facilities 2008-2009. ${ }^{41} \mathrm{We}$ calculated the distance to the nearest 
facility from the geographic centre of each census subdivision. We determined the mean number of family physicians per 1000 residents (hereafter family physicians per capita) by obtaining the number of family physicians/general practitioners practising in each economic zone by year in the study period from the Physician and Medical Practice Database and taking the mean. For beds per capita and family physicians per capita, we used the 2006 census population as the denominator. We assigned census subdivision-level values to patients for these 2 variables, as well as distance to nearest acute care facility, using postal code of residence.

\section{Statistical analysis}

We calculated means and proportions for outcomes and covariates by retention tertile. We did not calculate inferential bivariate comparison statistics (e.g., $\chi^{2}$ test or Kruskal-Wallis test), as the study was population-based and differences were actual differences. We used multivariate regression to model the association of retention tertile with number of hospital admissions for ambulatory-care-sensitive conditions, for all ages and for those aged 65 years or more, while adjusting for age, sex, income quintile, rural/urban residence status, Charlson Comorbidity Index score, proportion of population who reported having a high school diploma, proportion who were part of a visible minority and proportion reporting Aboriginal identity, distance to nearest acute care facility, number of acute care hospital beds per capita and number of family physicians per capita. We included factors in the final analysis only if $p<0.2$ in unadjusted analysis. We used the negative binomial model, as analysis revealed that the variance of hospital admissions (0.207) was larger than its mean (0.079), which indicated the presence of overdispersion, and the negative binomial model had better fit compared to Poisson regression based on a likelihood ratio test. ${ }^{42} \mathrm{We}$ also conducted a sensitivity analysis excluding urban patients given the high colinearity between retention tertile and place of residence. We carried out all analyses using IBM SPSS Statistics version 23 (IBM Corporation).

\section{Ethics approval}

The research protocol was approved by the Newfoundland and Labrador Health Research Ethics Board.

\section{Results}

In 2005-2009, there were 519269 residents with an active provincial health card and fixed place of residence. We excluded those in economic zones 1 and 4 (remote northern coastal areas in the Labrador region) ( $n=5266)$ from the analysis because economic zone 1 had no family physicians and economic zone 4 had 1 family physician for only a portion of the study period. Residents who died before 2005 were also excluded ( $n=14114)$, as were those who permanently left the province during 2001-2009 $(n=24198)$. Thus, the final study sample consisted of 475691 residents.

A total of 25265 residents $(5.3 \%)$ had at least 1 hospital admission for an ambulatory-care-sensitive condition. There were 38189 hospital admissions, yielding an average rate of admission for ambulatory-care-sensitive conditions of 78.8 per 1000 .

The mean retention rate was $53.5 \%$ (standard deviation 13.1 , range $13.8 \%-72.7 \%$ ).

Table 1 presents the proportions of patients in the physician retention tertile as well as descriptive statistics for covariates by tertile. Although there were differences in the covariates across tertiles, the difference in the proportion of rural patients was particularly notable.

The rate of admission for ambulatory-care-sensitive conditions per 1000 was 89.7 in the low retention tertile, 88.5 in the moderate tertile, 61.0 in the high tertile and 78.8 overall.

Table 2 presents the results of 3 multivariate negative binomial regression models showing factors associated with admission for ambulatory-care-sensitive conditions for the entire sample, for those aged 65 years or more and for those with rural residence. We excluded sex from the model because it was not a significant predictor in unadjusted analysis. After adjustment for covariates, there was a negative relation between retention tertile and admission for ambulatory-caresensitive conditions: residents in an economic zone with moderate physician retention had an increase of $16.5 \%$ (95\% confidence interval $12.6 \%-20.4 \%$ ) in the rate of admission relative to those in an economic zone with high retention, and residents in an economic zone with low retention had an even greater increase $(19.9 \%$ [95\% confidence interval $15.2 \%-$ $24.7 \%$ ) (Table 2). There was a similar but slightly more pronounced pattern in the analysis including rural residents only; however, no relation was seen in the analysis of those aged 65 years or more. In the multivariate analysis, all other covariates were significant predictors of admission for ambulatory-caresensitive conditions except for beds per capita.

\section{Interpretation}

We found a negative relation between family physician retention and hospital admission for ambulatory-care-sensitive conditions from 2005 to 2009 in a population-based cohort from Newfoundland and Labrador when controlling for other factors thought to affect admission.

The observed admission rates were similar to those in another Canadian study, in which the same ambulatory-caresensitive conditions were used. ${ }^{43}$ We also found admission rates for ambulatory-care-sensitive conditions to be higher in rural areas as well as among residents with higher comorbidity scores and those with lower household income, all of which have previously been reported..$^{30,44-48}$ The association between rurality and poor health has also been well documented ${ }^{49-52}$ and likely explains at least part of the association we observed between this factor and hospital admission rates. Hospital bed availability is commonly higher in rural areas, ${ }^{53}$ but the effect of rurality remained significant after we adjusted for beds per capita. In addition to higher comorbidity in rural areas, services that help keep patients out of hospital, such as home care, may be more readily available in urban areas, which may contribute to lower admission rates. 


\begin{tabular}{|c|c|c|c|c|}
\hline \multirow[b]{2}{*}{ Variable } & \multicolumn{3}{|c|}{ Physician retention tertile; no. (\%) of residents* } & \multirow[b]{2}{*}{$\begin{aligned} & \text { Total } \\
n= & 475691\end{aligned}$} \\
\hline & $\begin{aligned} \quad \text { Low } \\
n=152758\end{aligned}$ & $\begin{array}{c}\text { Moderate } \\
n=147399\end{array}$ & $\begin{array}{c}\text { High } \\
n=175534\end{array}$ & \\
\hline \multicolumn{5}{|l|}{ Sex } \\
\hline Male & $76520(50.1)$ & $74095(50.3)$ & $87193(49.7)$ & $237808(50.0)$ \\
\hline Female & $76231(49.9)$ & $73299(49.7)$ & $88326(50.3)$ & $237856(50.0)$ \\
\hline Missing & $7(<0.1)$ & $5(<0.1)$ & $15(<0.1)$ & $27(<0.1)$ \\
\hline \multicolumn{5}{|l|}{ Age, yr } \\
\hline Mean \pm SD & $37.8 \pm 22.6$ & $38.5 \pm 23.3$ & $34.9 \pm 23.6$ & $36.9 \pm 23.3$ \\
\hline Median & 39.0 & 40.0 & 36.0 & 38.0 \\
\hline \multicolumn{5}{|l|}{ Income quintile } \\
\hline Q1 (lowest) & $30072(19.7)$ & $28787(19.5)$ & $48714(27.8)$ & $107573(22.6)$ \\
\hline Q2 & $26797(17.5)$ & $36615(24.8)$ & $32342(18.4)$ & $95754(20.1)$ \\
\hline Q3 & $28805(18.8)$ & $31032(21.0)$ & $28996(16.5)$ & 88833 (18.7) \\
\hline Q4 & $28272(18.5)$ & 27741 (18.8) & 32104 (18.3) & 88117 (18.5) \\
\hline Q5 (highest) & $35309(23.1)$ & 21547 (14.6) & 32362 (18.4) & 89218 (18.8) \\
\hline Missing & 3503 (2.3) & 1677 (1.1) & $1016(0.6)$ & 6196 (1.3) \\
\hline \multicolumn{5}{|l|}{ Residence } \\
\hline Rural & $152758(100.0)$ & $95094(64.5)$ & $35986(20.5)$ & 283838 (59.7) \\
\hline Urban & $0(0.0)$ & 52305 (35.5) & $139548(79.5)$ & $191853(40.3)$ \\
\hline \multicolumn{5}{|l|}{$\begin{array}{l}\text { Charlson Comorbidity Index } \\
\text { score }\end{array}$} \\
\hline 0 & $108662(71.1)$ & 96419 (65.4) & $115160(65.6)$ & 320241 (67.3) \\
\hline $1-2$ & 24821 (16.2) & 27605 (18.7) & 33506 (19.1) & 85932 (18.1) \\
\hline $3-4$ & $10981(7.2)$ & 12200 (8.3) & $14255(8.1)$ & 37436 (7.9) \\
\hline$\geq 5$ & $8294(5.4)$ & $11175(7.6)$ & $12613(7.2)$ & $32082(6.7)$ \\
\hline $\begin{array}{l}\text { High school diploma, mean } \\
\pm \mathrm{SD}, \% \dagger\end{array}$ & $57.7 \pm 13.8$ & $61.4 \pm 12.2$ & $74.8 \pm 13.5$ & $65.2 \pm 15.2$ \\
\hline $\begin{array}{l}\text { Visible minority, mean } \pm \mathrm{SD} \text {, } \\
\% \dagger\end{array}$ & $1.0 \pm 2.0$ & $0.48 \pm 1.5$ & $1.9 \pm 3.4$ & $1.2 \pm 2.6$ \\
\hline $\begin{array}{l}\text { Aboriginal identity, mean } \\
\pm \mathrm{SD}, \% \dagger\end{array}$ & $6.0 \pm 14.3$ & $2.5 \pm 4.2$ & $3.7 \pm 8.2$ & $4.1 \pm 9.9$ \\
\hline $\begin{array}{l}\text { Distance to nearest acute } \\
\text { care facility, mean } \pm S D, k m\end{array}$ & $28.6 \pm 30.4$ & $26.4 \pm 27.9$ & $9.0 \pm 13.5$ & $20.7 \pm 26.2$ \\
\hline $\begin{array}{l}\text { Acute care hospital beds per } \\
1000 \text { residents, mean } \pm \text { SD }\end{array}$ & $2.2 \pm 1.2$ & $2.8 \pm 1.1$ & $3.1 \pm 1.0$ & $2.7 \pm 1.2$ \\
\hline $\begin{array}{l}\text { Family physicians per } \\
1000 \text { residents, mean } \pm \text { SD }\end{array}$ & $1.7 \pm 0.56$ & $1.6 \pm 0.23$ & $1.4 \pm 0.16$ & $1.6 \pm 0.37$ \\
\hline $\begin{array}{l}\text { Note: SD = standard deviation. } \\
{ }^{*} \text { Except where noted otherwise. } \\
\text { †Data represent mean percentag }\end{array}$ & comination & ion tertile. & & \\
\hline
\end{tabular}

If the association is causal, the exact mechanism by which physician retention exerts its effects on hospital admission is not fully understood, although quality of communication, comprehensiveness of physician knowledge about the patient and certain characteristics of the patient-provider relationship are thought to play a major role. ${ }^{13,26,27}$ Even if medical records and communication between providers are excellent, there are likely factors that are not typically recorded in patient charts that affect clinician and patient decision-making. These factors may become apparent only when a clinician and patient develop a lasting, trusting relationship. Other studies have shown a relation between physician retention/turnover and improved patient satisfaction and higher rates of preventive services, although evidence is conflicting. ${ }^{24-27,29}$ 
Table 2: Factors associated with hospital admission for ambulatory-care-sensitive conditions*

\begin{tabular}{|c|c|c|c|}
\hline \multirow[b]{2}{*}{ Variable } & \multicolumn{3}{|c|}{ Rate ratio $(95 \% \mathrm{Cl}) \dagger$} \\
\hline & All ages & Age $\geq 65 \mathrm{yr}$ & Rural residence \\
\hline \multicolumn{4}{|l|}{ Physician retention tertile } \\
\hline Q1 (lowest) & $1.199(1.152-1.247)$ & 1.047 (0.968-1.133) & $1.232(1.168-1.299)$ \\
\hline Q2 & $1.165(1.126-1.204)$ & $1.001(0.943-1.075)$ & $1.198(1.135-1.265)$ \\
\hline Q3 (highest) (reference) & 1.000 & 1.000 & 1.000 \\
\hline Age & $0.999(0.998-0.999)$ & $1.008(1.004-1.011)$ & $1.002(1.001-1.003)$ \\
\hline \multicolumn{4}{|l|}{ Income quintile } \\
\hline Q1 (lowest) & $1.212(1.162-1.264)$ & 1.177 (1.084-1.277) & $1.178(1.118-1.241)$ \\
\hline Q2 & $1.166(1.121-1.214)$ & $1.135(1.049-1.228)$ & $1.131(1.076-1.188)$ \\
\hline Q3 & $1.133(1.088-1.179)$ & $1.070(0.989-1.159)$ & $1.116(1.062-1.172)$ \\
\hline Q4 & 1.145 (1.101-1.190) & 1.165 (1.077-1.261) & $1.165(1.110-1.221)$ \\
\hline Q5 (highest) (reference) & 1.000 & 1.000 & 1.000 \\
\hline \multicolumn{4}{|l|}{ Residence status } \\
\hline Rural & 1.198 (1.157-1.365) & $1.302(1.217-1.393)$ & - \\
\hline Urban (reference) & 1.000 & 1.000 & \\
\hline \multicolumn{4}{|l|}{$\begin{array}{l}\text { Charlson Comorbidity Index } \\
\text { score }\end{array}$} \\
\hline 0 & $0.086(0.083-0.089)$ & $0.113(0.104-0.123)$ & $0.093(0.090-0.098)$ \\
\hline $1-2$ & $0.267(0.258-2.276)$ & $0.430(0.405-0.457)$ & $0.290(0.279-1.303)$ \\
\hline $3-4$ & $0.396(0.382-0.411)$ & $0.580(0.549-0.614)$ & $0.423(0.404-0.441)$ \\
\hline$\geq 5$ (reference) & 1.000 & 1.000 & 1.000 \\
\hline High school diplomał & $0.991(0.990-0.992)$ & $0.990(0.987-0.991)$ & $0.990(0.989-0.991)$ \\
\hline Visible minority $\ddagger$ & $0.993(0.987-0.998)$ & $0.992(0.982-1.002)$ & $0.981(0.972-0.990)$ \\
\hline Aboriginal identity $\ddagger$ & $1.006(1.005-1.007)$ & 1.006 (1.003-1.009) & $1.007(1.006-1.008)$ \\
\hline $\begin{array}{l}\text { Distance to nearest acute care } \\
\text { facility } \ddagger\end{array}$ & $0.998(0.997-0.998)$ & $0.998(0.997-0.999)$ & $0.997(0.997-0.998)$ \\
\hline $\begin{array}{l}\text { Acute care hospital beds per } \\
1000 \text { residents } \ddagger\end{array}$ & $1.000(0.990-1.010)$ & $0.998(0.980-1.016)$ & $1.003(0.992-1.014)$ \\
\hline $\begin{array}{l}\text { Family physicians per } \\
1000 \text { residents } \ddagger\end{array}$ & $1.363(1.318-1.409)$ & $1.261(1.175-1.352)$ & $1.346(1.300-1.394)$ \\
\hline $\begin{array}{l}\text { Note: } \mathrm{Cl}=\text { confidence interval. } \\
{ }^{*} \text { Analysis excludes } 7989 \text { residents with } \\
\text { †Equal to the exponent of the regressio } \\
\text { †lncluded in continuous form in the fina }\end{array}$ & $\begin{array}{l}\text { g data for } 1 \text { or more cove } \\
\text { ficient and adjusted for a }\end{array}$ & $\begin{array}{l}\text { ess than } 1 \% \text { of sample). } \\
\text { ariables in the table. }\end{array}$ & \\
\hline
\end{tabular}

We expected the relation between physician retention and hospital admission to be more pronounced for older adults; however, we did not find such a relation. We had thought that family physicians in areas with higher retention would have a better understanding of the higher levels of social complexity and multimorbidity in this population and, thus, have a better ability to mitigate their effect on hospital admission. The lack of relation may be associated with a higher likelihood of involvement of specialist and/or nonphysician providers in the care of older patients.

Another unexpected result was the positive relation observed between admission for ambulatory-care-sensitive conditions and number of family physicians in the region. A review of the literature, however, revealed that the small num- ber of studies in this area have had mixed results, with studies reporting results similar to ours (no relation) or the expected inverse (negative) relation. ${ }^{54-58}$ In addition, a randomized controlled trial of US Veterans Affairs medical centers showed that patients who received a greater amount of primary care after hospital discharge had higher rather than lower hospital readmission rates. ${ }^{59}$

\section{Strengths and limitations}

The main strengths of this study are its use of large administrative databases representing the provincial population, which allowed for comprehensive analysis, as well as controlling for many factors affecting hospital admission for ambulatory-caresensitive conditions. The study is limited by its cross-sectional 
design involving measurement of physician retention and hospital admission over the same period, which allowed for determination of an association between these 2 variables but prevented us from making conclusions about causality. The observational study design may also be associated with possible residual confounding owing to between-group differences in unknown or unmeasured variables, or the level of measurement of variables. An example of the latter is physician retention, which was calculated at the level of economic zone and can represent a fairly large geographic area. Although retention values in the current study provide an aggregate measure of retention within the economic zone, actual retention levels experienced by patients within different communities or neighbourhoods within a given economic zone may be different depending on local physician migration patterns and access to physicians outside the economic zone of residence. Also, we were not able to measure other factors that may have affected outcomes, such as disease severity or comorbidities not captured within the Charlson Comorbidity Index, lifestyle choices, motivation to seek care, compliance with treatment, extent of care from specialist or nonphysician providers, other access barriers, variation in physician practice patterns/hospital admission thresholds and differences between regions in environmental factors such as pollution, poor housing and unhealthy working conditions. ${ }^{54,58,60,61}$ In addition, although there were exclusions from the study sample, such as residents who migrated outside the province, they amounted to less than $10 \%$ of the study population and, thus, were arguably associated with very little bias. Finally, although retention data were available for all family physicians in the province through the Physician and Medical Practice Database, physician use data (i.e., physician claims) in the province included only fee-forservice physicians. Data on use were unavailable for visits to the roughly $35 \%$ of physicians in the province who were not remunerated on a fee-for-service basis, most of whom were located in rural areas. Thus, determination of patterns of continuity of care across the province was not possible, and the Charlson Comorbidity Index score, which uses diagnostic codes from physician claims, may have been underestimated for patients in rural areas.

\section{Conclusion}

The current study shows that physician retention in a given region is highly associated with hospital admission for ambulatory-care-sensitive conditions, a finding that should be of interest to clinicians and decision-makers. Although this finding is likely explained at least in part by a reduction in continuity of care, it is also important because the policy response to this finding may be different. We argue that efforts should be made not only to improve continuity of care but also to minimize physician turnover in a region. Physician retention may also be an appropriate proxy for continuity of care when it is not possible to measure continuity at the individual level. Future research should examine additional factors affecting rates of admission for ambulatory-care-sensitive conditions not accounted for in this study, such as primary care use, other patient and physician characteristics, and envi- ronmental factors, in addition to involving different measures of retention/turnover and testing effects of retention on other important outcomes such as emergency department visits, health care costs and mortality. We plan to investigate measuring retention at the level of emergency department catchment area, thus more accurately capturing retention at the local level. In addition, more powerful longitudinal study designs where physician retention is shown to precede hospital admission would more effectively show a causal effect of physician retention on avoidable hospital admission.

\section{References}

1. Gulbrandsen P, Hjortdahl P, Fugelli P. General practitioners' knowledge of their patients' psychosocial problems: multipractice questionnaire survey. $B M 7$ 1997;314:1014-8.

2. Mainous AG 3rd, Kern D, Hainer B, et al. The relationship between continuity of care and trust with stage of cancer at diagnosis. Fam Med 2004;36:35-9.

3. Gulliford MC, Naithani S, Morgan M. Continuity of care and intermediate outcomes of type 2 diabetes mellitus. Fam Pract 2007;24:245-51.

4. Fenton JJ, Franks P, Reid RJ, et al. Continuity of care and cancer screening among health plan enrollees. Med Care 2008;46:58-62.

5. Saultz JW, Albedaiwi W. Interpersonal continuity of care and patient satisfaction: a critical review. Ann Fam Med 2004:2:445-51.

6. Kelly RB, Shank JC. Adherence to screening flexible sigmoidoscopy in asymptomatic patients. Med Care 1992;30:1029-42.

7. Safran DG, Taira DA, Rogers WH, et al. Linking primary care performance to outcomes of care. 7 Fam Pract 1998;47:213-20.

8. Hjortdahl P, Laerum E. Continuity of care in general practice: effect on patient satisfaction. BM7 1992;304:1287-90.

9. Weyrauch KF. Does continuity of care increase HMO patients' satisfaction with physician performance? 7 Am Board Fam Pract 1996;9:31-6.

10. Christakis DA, Wright JA, Koepsell TD, et al. Is greater continuity of care associated with less emergency department utilization? Pediatrics 1999;103: 738-42.

11. Menec VH, Sirski M, Attawar D. Does continuity of care matter in a universally insured population? Health Serv Res 2005;40:389-400.

12. Ionescu-Ittu R, McCusker J, Ciampi A, et al. Continuity of primary care and emergency department utilization among elderly people. CMAf 2007;177: 1362-8.

13. Mainous AG 3rd, Gill JM. The importance of continuity of care in the likelihood of future hospitalization: Is site of care equivalent to a primary clinician? Am 7 Public Health 1998;88:1539-41.

14. Menec VH, Sirski M, Attawar D, et al. Does continuity of care with a family physician reduce hospitalizations among older adults? $\mathcal{f}$ Health Serv Res Policy 2006;11:196-201.

15. Knight JC, Dowden JJ, Worrall GJ, et al. Does higher continuity of family physician care reduce hospitalizations in elderly people with diabetes? Popul Health Manag 2009;12:81-6.

16. Starfield B, Chang HY, Lemke KW, et al. Ambulatory specialist use by nonhospitalized patients in us health plans: correlates and consequences. $7 \mathrm{Ambul}$ Care Manage 2009;32:216-25.

17. Nyweide DJ, Anthony DL, Bynum JPW, et al. Continuity of care and the risk of preventable hospitalization in older adults. 7AMA Intern Med 2013;173:1879-85.

18. Cornelius LJ. The degree of usual provider continuity for African and Latino Americans. F Health Care Poor Underserved 1997;8:170-85.

19. De Maeseneer JM, De Prins L, Gosset C, et al. Provider continuity in family medicine: Does it make a difference for total health care costs? Ann Fam Med 2003;1:144-8.

20. Hollander MJ, Kadlec H, Hamdi R, et al. Increasing value for money in the Canadian healthcare system: new findings on the contribution of primary care services. Healthc Q 2009;12:32-44.

21. Wolinsky FD, Bentler SE, Liu L, et al. Continuity of care with a primary care physician and mortality in older adults. 7 Gerontol A Biol Sci Med Sci 2010;65: 421-8.

22. Worrall G, Knight J. Continuity of care is good for elderly people with diabetes: retrospective cohort study of mortality and hospitalization. Can Fam Physician 2011;57:e16-20

23. Lustman A, Comaneshter D, Vinker S. Interpersonal continuity of care and type two diabetes. Prim Care Diabetes 2016;10:165-70.

24. Ruhe M, Gotler RS, Goodwin MA, et al. Physician and staff turnover in community primary care practice. 7 Ambul Care Manage 2004;27:242-8.

25. Pereira AG, Kleinman KP, Pearson SD. Leaving the practice: effects of primary care physician departure on patient care. Arch Intern Med 2003;163: 2733-6.

26. Plomondon ME, Magid DJ, Steiner JF, et al. Primary care provider turnover and quality in managed care organizations. Am 7 Manag Care 2007;13:465-72. 
27. Reddy A, Pollack CE, Asch DA, et al. The effect of primary care provider turnover on patient experience of care and ambulatory quality of care. 7 AMA Intern Med 2015;175:1157-62.

28. Kahana E, Strange KC, Meehan R, et al. Forced disruption in continuity of primary care: the patient's perspective. Sociol Focus 1997;30:177-87.

29. Misra-Hebert AD, Kay R, Stoller JK. A review of physician turnover: rates, causes, and consequences. Am 7 Med Qual 2004;19:56-66.

30. Billings J, Zeitel L, Lukomnik J, et al. Impact of socioeconomic status on hospital use in New York City. Health Aff (Millwood) 1993;12:162-73.

31. Supply, distribution and migration of physicians in Canada, 2015: data tables. Ottawa: Canadian Institute for Health Information; 2016.

32. Clinical Database Management System (CDMS) data users guide V.1.0. St. John's: Newfoundland and Labrador Centre for Health Information; 2014.

33. NLCHI Mortality System data users guide V.1.2. St. John's: Newfoundland and Labrador Centre for Health Information; 2014.

34. Segovia J, Edwards AC. Newfoundland panel on health and medical care utilization 1992-9: final report. St. John's: Division of Community Medicine, Faculty of Medicine, Memorial University of Newfoundland; 2001.

35. Postal Code Conversion File (PCCF), reference guide. Cat no 92-153-XCB. Ottawa: Statistics Canada; 2009

36. 2006 census dictionary. Cat no 92-566-XWE. Ottawa: Statistics Canada; 2007.

37. Economic zones: Newfoundland and Labrador [map]. St. John's: Department of Finance, Newfoundland and Labrador Statistics Agency; 2011. Available: www.stats.gov.nl.ca/Maps/pdfs/EZ_NL.pdf (accessed 2017 July 17).

38. Alameddine M, Laporte A, Baumann A, et al. 'Retention' and 'inflow' as proxy measures of the relative attractiveness of various sub-sectors of nursing employment. Soc Sci Med 2006;63:2310-9.

39. Lavoie JG, Forget EL, Prakash T, et al. Have investments in on-reserve health services and initiatives promoting community control improved First Nations' health in Manitoba? Soc Sci Med 2010;71:717-24.

40. Sundararajan V, Henderson T, Perry C, et al. New ICD-10 version of the Charlson Comorbidity Index predicted in-hospital mortality. 7 Clin Epidemiol 2004;57:1288-94.

41. Canadian Healthcare Association. Guide to Canadian bealthcare facilities 20082009. vol. 16. Ottawa: CHA Press; 2008.

42. Booth JG, Casella G, Friedl H, et al. Negative-binomial loglinear mixed models. Stat Model 2003;3:179-91.

43. Lavoie JG, Forget EL, Dahl M, et al. Is it worthwhile to invest in home care? Healthc Policy 2011;6:35-48.

44. Billings J, Anderson GM, Newman LS. Recent findings on preventable hospitalizations. Health Aff (Millwood) 1996;15:239-49.

45. McConnochie KM, Roghmann KJ, Liptak GS. Socioeconomic variation in discretionary and mandatory hospitalization of infants: an ecologic analysis. Pediatrics 1997;99:774-84.

46. Cloutier-Fisher D, Penning MJ, Zheng C, et al. The devil is in the details: trends in avoidable hospitalization rates by geography in British Columbia, 1990-2000. BMC Health Serv Res 2006;6:104.

47. Roos LL, Walld R, Uhanova J, et al. Physician visits, hospitalizations, and socioeconomic status: ambulatory care sensitive conditions in a Canadian setting. Health Serv Res 2005;40:1167-85.

48. Agha MM, Glazier RH, Guttmann A. Relationship between social inequalities and ambulatory care-sensitive hospitalizations persists for up to 9 years among children born in a major Canadian urban center. Ambul Pediatr 2007;7:258-62.

49. How beathy are rural Canadians? An assessment of their health status and bealth determinants [summary report]. Ottawa: Canadian Institute for Health Information; 2006.
50. Badgley RF. Social and economic disparities under Canadian health care. Int 7 Health Serv 1991;21:659-71.

51. Mansfield CJ, Wilson JL, Kobrinski EJ, et al. Premature mortality in the United States: the roles of geographic area, socioeconomic status, household type, and availability of medical care. Am 7 Public Health 1999;89:893-8.

52. Pampalon R. Health discrepancies in rural areas in Quebec. Soc Sci Med 1991; 33:355-60.

53. Finch LE, Christianson JB. Rural hospital costs: an analysis with policy implications. Public Health Rep 1981;96:423-33.

54. Laditka JN, Laditka SB, Probst JC. More may be better: evidence of a negative relationship between physician supply and hospitalization for ambulatory care sensitive conditions. Health Serv Res 2005;40:1148-66.

55. Krakauer H, Jacoby I, Millman M, et al. Physician impact on hospital admission and on mortality rates in the Medicare population. Health Serv Res 1996; 31:191-211.

56. Ricketts TC, Randoph R, Howard HA, et al. Hospitalization rates as indicators of access to primary care. Health Place 2001;7:27-38.

57. Parchman ML, Culler S. Primary care physicians and avoidable hospitalizations. 7 Fam Pract 1994;39:123-8.

58. Schreiber S, Zielinski T. The meaning of ambulatory care sensitive admissions urban and rural perspectives. 7 Rural Health 1997;13:276-84.

59. Weinberger M, Oddone EZ, Henderson WG. Does increased access to primary care reduce hospital admissions? Veterans Affairs Cooperative Study Group on Primary Care and Hospital Readmission. N Engl 7 Med 1996;334: 1441-7.

60. Komaromy M, Lurie N, Osmond D, et al. Physician practice style and rates of hospitalization for chronic medical conditions. Med Care 1996;34:594-609.

61. Donaldson M, Yordy K, Lohr K, et al., editors. Primary care: America's bealth in a new era. Washington: National Academy Press, Institute of Medicine; 1996.

Affiliations: Primary Healthcare Research Unit (Knight, AubreyBassler), Faculty of Medicine, Memorial University; Newfoundland and Labrador Centre for Health Information (Knight); Division of Community Health and Humanities (Knight, Mathews) and Discipline of Family Medicine (Aubrey-Bassler), Faculty of Medicine, Memorial University, St. John's, Nfld.

Contributors: John Knight and Maria Mathews contributed substantially to study conception and design and to data acquisition, analysis and interpretation. John Knight drafted the manuscript. Kris Aubrey-Bassler was principal investigator of the overall research project and contributed substantially to study conception and design and to data acquisition and interpretation. All of the authors revised the manuscript for intellectual content, gave final approval of the version to be published and agreed to be accountable for all aspects of the work.

Funding: This study was supported by grants from the Canadian Institutes of Health Research and the Research \& Development Corporation awarded to Kris Aubrey-Bassler through the Regional Partnerships Program.

Supplemental information: For reviewer comments and the original submission of this manuscript, please see www.cmajopen.ca/content/5/4/ E746/suppl/DC1. 